\title{
A successful Charter challenge to medicare? Policy options for Canadian provincial governments
}

\author{
COLLEEN M. FLOOD* \\ Professor, Faculty of Law and Director, Centre for Health Law, Policy and Ethics, University of Ottawa, Ottawa, ON, \\ Canada \\ BRYAN THOMAS \\ Research Associate, Centre for Health Law, Policy and Ethics, University of Ottawa, Ottawa, ON, Canada
}

\begin{abstract}
In September 2016, a case went to trial in British Columbia that seeks to test the constitutionality of provincial laws that (1) ban private health insurance for medically necessary hospital and physician services; (2) ban extra-billing (physicians cannot charge patients more than the public tariff); and (3) require physicians to work solely for the public system or 'opt-out' and practice privately. All provinces have similar laws that have been passed to meet the requirements of federal legislation, the Canada Health Act (and thus qualify for federal funds). Consequently, a finding of unconstitutionality of one or more of these laws could have a very significant impact on the future of Canada's single-payer system ('medicare'). However, should the court find that a particular law is not in compliance with the Canadian Charter of Rights and Freedoms, the baton is then passed back to the government which may respond with other laws or policies that they believe to be constitutionally compliant. The ultimate impact of any successful Charter challenge to laws protecting medicare from privatization will thus significantly depend on how Canadian governments respond. Provincial governments could allow privatization to undercut equity and access, or they could respond creatively with new legal and policy solutions to both improve equity and access and tackle some of the problems that have long bedeviled Canadian medicare. This paper provides an understanding - grounded in comparative health systems evidence of law and policy options available to Canadian lawmakers for limiting two-tier care in the wake of any successful challenge to existing laws. The paper presents the results of a large inter-disciplinary, comparative study, started in 2015, that systematically reviewed the legal and broader regulatory schemes used to regulate the public/private divide in 15 Organization for Economic Co-Operation and Development countries with a particular eye to what the effect of such regulations would be upon wait times.
\end{abstract}

Submitted 1 April 2017; revised 19 May 2017; accepted 1 July 2017; first published online 26 March 2018

*Correspondence to: Professor Colleen M. Flood, Faculty of Law and Director, Centre for Health Law, Policy and Ethics, University of Ottawa, Ottawa, ON, Canada K1N 6N5. Email: colleenmarionflood@gmail.com 


\section{Introduction}

Across Canada, laws designed to protect public medicare are subject to court challenges on the grounds that a public monopoly on health care subjects Canadians to long wait times, infringing the right to 'life, liberty and security of the person', guaranteed under the Canadian Charter of Rights and Freedoms. By way of remedy, the claimants demand the liberalization of privately financed care, to create a 'safety valve' for wait times in the public system. The most prominent of these challenges (the Cambie trial), led by Cambie Surgical Services, a private clinic headed by Dr Brian Day, challenges various laws in British Columbia that prohibit physicians in the public system from extra-billing patients and moonlighting in the private sector, and also prohibit private health insurance for services covered by medicare (parallel private insurance). Although the litigation appears temporarily stalled as the applicants allege they need more financial resources (Mulgrew, 2017), it nonetheless seems likely that in the coming years, the Supreme Court of Canada ('the Court') will be called upon to rule on Cambie or a similar Charter challenge, setting an uncharted course for Canadian medicare. In its 2005 Chaoulli ruling, the Court ordered the province of Quebec to lift its restrictions on parallel private insurance, suspending its declaration of invalidity for a year to allow time for government to draft response legislation (Roach, 2005). Research is urgently needed into alternative approaches to regulating the public/private divide, as current and future court challenges may present governments with a similarly brief window to respond.

These Charter challenges will consider international comparative evidence, as applicants contend that Canada's regulation of physician billing and private insurance are arbitrary or over-broad given the gravity of the rights impacted (and thus unconstitutional), because other countries maintain viable universal schemes without prohibiting a parallel private tier. This oft-made claim rest generally upon a superficial analysis of foreign health care systems; in fact a number of countries employ various laws and policies to restrict two-tier care, though there has been limited research on these approaches to date (Flood and Haugan, 2010). In what follows we present the results of research into 15 jurisdictions exploring how two-tier health care is regulated and consider the extent to which these approaches could be employed in the specific Canadian context following a successful constitutional challenge to one or more of the laws currently in place. ${ }^{1}$ We argue that the specific history and context of provincial Canadian systems support the government's case that the present restrictions are reasonable and not arbitrary or over-broad.

\section{A brief overview of laws protecting Canadian medicare}

Marchildon has well laid out the political and legal history of medicare leading to the adoption of the Canada Health Act (CHA) (Marchildon, 2014). As he

1 The country reports are available online at http://ottawahealthlaw.ca/twotiercomparative 
discusses, the CHA itself supports single-tier universal health coverage, that is, access for all on uniform terms. It does this by conditioning federal funding upon the provinces' committing to 'accessibility' and specifically by prohibiting extra-billing (where physicians or hospitals charge patients a sum on top of what government pays them) and user charges (where the government itself requires the payment of charges) for medically necessary physician and hospital services.

To qualify for federal funding, each province has enacted some mix of the following statutory prohibitions:

a. laws banning extra-billing;

b. laws banning user charges;

c. laws banning parallel private health insurance for publicly insured services (supplementary private health insurance is permitted and common for things such as prescription drugs and dental);

d. laws requiring doctors to either 'opt-in' to public medicare or 'opt-out', and in the latter case being prohibited from billing public medicare for any services;

e. laws restricting the prices that physicians who have opted-out can charge patients for medically necessary care.

After a period of fierce resistance from physician groups, Canada eventually settled into these rules for regulating the public/private divide. Then a frenzy of deficit fighting under the Chrétien government of the mid-1990s saw a clawback of federal health transfers, which, combined with fiscal challenges at the provincial level, resulted in hospital closures and growing wait times for specialist care across the country (Tuohy et al., 2004). This in turn set the stage for court challenges to the pillars of medicare, as physicians recast their longstanding demand for increased individual control over billing and greater privatization as claims around patient rights. In the ground-breaking Chaoulli case, Quebec's ban on private health insurance was challenged by Jacques Chaoulli, a physician looking to open a private hospital, and George Zeliotis, a septuagenarian businessman with multiple medical conditions, allegedly facing long wait times in the public system. Together, the plaintiffs alleged that Quebec's law prohibiting parallel private insurance for medically necessary hospital and physician services breached patients' right to life and security of the person, as guaranteed under s. 1 of Quebec's Charter of Human Rights and Freedoms and s. 7 of the Canadian Charter.

In a 4-to-3 decision, the Supreme Court sided with the applicants' claim made under the Quebec Charter, and overturned the law restricting parallel private insurance. However, the ruling had no immediate impact on laws in other provinces because there was no majority consensus on how the national Charter applied, necessitating the need for privatization proponents to bring separate litigation in other provinces such as the Cambie challenge in British Columbia. Writing for the majority in Chaoulli, Justice Deschamps found that, given unreasonable wait times in the public system, patients' rights in Quebec were unjustifiably infringed by provincial laws prohibiting private insurance. Lawyers for the Quebec and 
Canadian governments had argued that restrictions on parallel private insurance were necessary to protect the supply of physician services in the public system. The majority judges rebuffed this argument, relying on (in our opinion) a superficial review of international evidence to conclude that most Western European countries manage to maintain high performing public systems while allowing a parallel private tier (Flood, 2008).

But looking just past the immediate point of the Supreme Court's decision itself, even within the province of Quebec we did not see widespread privatization. ${ }^{2}$ This is because the Quebec government, in responding to the ruling, implemented laws and policies that complied with the decision in the narrowest way possible liberalizing private insurance for only a few categories of elective surgical procedures where wait times were extremely long (e.g. hip replacement). But arguably the Chaoulli decision had a more long-term normative effect, with recent evidence that many of Quebec's existing laws limiting private finance (e.g. extra-billing) are being broken (Shingler and Montpetit, 2016; Ontario Health Coalition, 2017). Nationwide, as explained, the application of the federal Charter remains unsettled. Moreover, Chaoulli's impact as a precedent has been blunted by the fact that the provinces employ multiple regulatory tools, apart from banning duplicative private insurance, to tamp down privately financed care (see above). Privatization advocates have woken up to this reality and in the Cambie litigation are now seeking not only the overturn of BC's ban on private health insurance, but the overturn of all laws restricting two-tier care (i.e. laws prohibiting dual practice, extra-billing, user charges and price restrictions on physicians who practice privately in some circumstances).

In the light of all of this and the potential for large-scale policy change to be forced upon Canadian governments by the courts, it is essential to have evidence on alternative approaches to regulating two-tier care (or parallel private finance), for two reasons. First, this evidence will be important for the court as it considers whether existing regulations have a disproportionate impact on individual rights. In asking itself this question, a court will want evidence of what other democratic countries do to limit two-tier care and compare this evidence with Canada's approach. If a court then finds that Canada's approach is arbitrary or disproportionately restrictive of parallel private finance, then the ball will be in the government's court in the sense that the court most likely will give a provincial government like $\mathrm{BC}$ some time to come up with a policy response - a substitute scheme for regulating the public/private divide that eliminates or minimizes the supposed conflict with Charter rights (Hogg and Bushell, 1997; Manfredi, 2005; Roach, 2005). That response legislation will need to be well supported by international evidence if for no other reason than that it may be more likely to

2 The majority in Chaoulli only reached consensus that prohibitions on duplicative private insurance infringe the Quebec Charter of Human Rights and Freedoms. Whether such prohibitions infringe the national Charter of Rights and Freedoms was left undecided, meaning that the question would have to be re-litigated to determine whether the Chaoulli precedent on private insurance applies to other provinces. 
withstand another Charter challenge in the future. To date there are no studies that systematically compare the regulation of two-tier care across countries. To fill this gap, we brought together an inter-disciplinary team of leading legal and policy experts from around the world to illuminate our understanding of laws and policies vis-à-vis two-tier care across 15 Organization for Economic Co-Operation and Development (OECD) countries. What follows is an overview of our relevant findings to date.

\section{How other countries regulate the public-private divide}

It is worth explaining from the outset that some countries that figure prominently in debates about two-tier care and the benefits of private insurance in fact embrace forms of 'private health insurance' that have little to do with what is being actually mooted in the Canadian context, yet are frequently employed as examples of what Canada could be like if various law protecting public medicare were overturned. For example, Dr Day (2015), principal owner of the Cambie surgical clinic, frequently refers to 'hybrid' systems like Germany and the Netherlands, suggesting their permissive approach to private finance reveals the irrationality of the Canadian model. But in Germany, for example, wealthier individuals are allowed only to opt-out entirely from the country's universal social health insurance scheme, and choose to 'go private' - but must then enrol in a comprehensive private plan covering all needs. The incentive here is that young, healthy individuals may realize savings by buying private insurance in lieu of contributing income-adjusted premiums to the social health insurance scheme. Our research suggests that there are equity concerns in Germany's system, with private patients receiving faster access to specialist appointments (Frisina and Schmid, 2016). But the larger point is that the German model of substitutive private insurance is not under debate in the Canadian context - those agitating for a greater role for the private sector in Canada are very clear that they want patients to be covered by public insurance and then to use parallel private finance (insurance or out-ofpocket payments) in order to jump public queues (or in their parlance to utilize a 'safety valve') (Cambie Surgeries et al., 2016). Similarly, false comparisons are often drawn to the Dutch system which is a 'managed competition' scheme, wherein virtually all residents are required (and receive subsidies if necessary) to buy coverage from a private insurer again, for all their health care needs. Again, the Netherlands' use of private health insurance bears no resemblance to what Canadian privatizers argue for - the Dutch use heavily regulated private insurance as a mechanism for achieving universality, not as a means to circumvent wait times in the public system (den Exter, 2016). As yet another kind of example of the differing roles for private insurance across different health care systems, it is of note that the primary role for private health insurance in France (which over $90 \%$ of the population holds) is to cover the cost of co-payments, which are levied on all treatments (Chevreul et al., 2015). Thus, the existence of private insurance 
in France and its role vis-à-vis two-tier care cannot be divorced from this primary purpose. Consequently, while these countries' experiences may offer some lessons to Canada, their overarching approach to the public/private divide is inapplicable to the core issues under debate in the Cambie trial. Nevertheless, these countries are frequently held up as models of what the Canadian system could be if only two-tier care were allowed - an indication of how comparative evidence is misused in Canadian debates.

Further, apart from mischaracterizing the varied roles that private insurance and finance play in different systems, another failing on the part of those promoting privatization in the Canadian system is to portray Canada as the only country that puts any limits on the existence of a parallel private tier. In fact, in pursuit of maintaining equitable access, many high-income countries take steps to regulate privately financed care. The rationale is commonsensical: universal health care systems aspire to ensure access on the basis of medical need, whereas the intrusion of a private market will divert resources to patients on the basis of ability to pay. In concrete terms, the primary concern is that a flourishing private tier will syphon medical human resources, resulting in greater inequity and in longer wait times in the public system. An additional concern is that the private tier's attempts to outbid the public system will drive up prices in the public system overall (e.g. the public system will have to pay a higher unit price for medical manpower or else providers will increasingly drift to a higher-paying private sector).

Of course, regulating private finance is not an all-or-nothing affair: it is possible to maintain a functioning public system while tolerating some role for a parallel private tier, and as we will see, countries vary here both in their choice of regulatory instruments and in their level of regulatory zeal. But without doubt, permitting that tier both undermines and complicates the goal of equity, namely achieving access on the basis of need and not ability to pay. Further, the choice of regulatory instrument needs to reflect the particular context of the system, including historical choices made around the level of autonomy for physicians and how they are paid. Moreover, though our discussion will focus on law and regulations, these are by no means the whole story when it comes to explaining the level of privately financed care within a country; many background factors are also at play. A country's overall economic climate is also an important factor, as our research finds that levels of parallel private insurance decline significantly during economic recessions - even in countries like Ireland, where incentives strongly support a parallel private tier (Thomas, 2016).

\section{Financial disincentives on the demand side of the health care services market}

A natural place to begin is with regulations that tamp demand for privately financed care, targeting patients themselves through restrictions or penalties for parallel private finance. The law challenged in Chaoulli fit in this category - a 
statutory prohibition on private insurance contracts for health services that fall within the medicare basket, ${ }^{3}$ effectively limiting demand for private care to those able to cover the costs out-of-pocket. Variations here include pseudo-tax measures that compel private-tier patients to effectively cross-subsidize care in the public system. Saskatchewan is currently experimenting with one such approach, through provisions of the Patient Choice Medical Imaging Act that require private magnetic resonance imagings (MRIs) clinics to provide one scan free of charge to the public system for every scan sold privately. Such a measure likely increases the price that consumers pay for the MRI, thus diminishing the incentive to they have to demand such a service in the parallel pay system.

Interestingly, a variation on this approach can be found even in the United States - a country not known for vigilantly safeguarding equity across the public/ private divide. One of the more controversial features of the US Affordable Care Act ('Obamacare') is an excise tax on so-called 'Cadillac' private insurance plans, set to come into force in 2020 (Mantel and Westergren, 2016). The tax is designed to discourage overuse of care in the private tier, correct the disproportionate tax benefit that results from the tax deductibility of employer-provided insurance, and generate revenue towards expanding coverage for other Americans (e.g. those receiving Medicaid or subsidies to purchase care on the exchanges) (Piotrowski, 2013).

Demand-side disincentives have also been used to discourage a unique form of two-tier care that occurs when private finance is used to purchase expensive and unproven therapies that are excluded from the public basket on grounds of cost effectiveness (e.g. cancer drugs that are extremely expensive relative to the quality and length of life which results). Private access to such therapies raises equity concerns especially when, for example, a patient seeks such treatments while being cared for in a public hospital (Flood and Hardcastle, 2007). The issue has been hotly debated in Japan, following the enactment of regulations that formally prohibit 'combined billing' of public and private care. Patients wishing to pay privately for treatments not covered by the public plan - because of their cost or because they are experimental - must bear all of the associated costs for that 'episode' of care providers who attempt to bill the country's social health insurance scheme for public components of such care are subject to administrative penalties. Critics argue that allowing combined billing will spur technological advancement, and have challenged the legal basis for the regulation - though ultimately Japan's Supreme Court found it to be valid (Kasagi and Kawaguchi, 2016).

A similar debate has taken place in the United Kingdom, which until 2009 required that any given treatment be funded entirely within the National Health Service (NHS) or entirely privately (UK Department of Health, 2004)

3 One could see this as a supply-side policy as the regulation applies to insurance providers, prohibiting them from offering policies that include publicly insured services. It does not prohibit individuals from purchasing such policies, were they to exist. However, the net effect is to affect the supply side in the sense of diminishing the funds patients have on hand to purchase parallel private care. 
The current guidance allows combined billing, but requires that the public and private components be kept as separate as possible (i.e. that the private component be carried out at a different time/location, and not use NHS equipment to the detriment of public patients) (UK Department of Health, 2009; Botchway and Newdick, 2016).

To be clear, we are not suggesting that all OECD countries have regulatory measures in place to limit on inhibit demand for private care. Indeed, some countries positively embrace parallel private finance as an accompaniment to their universal schemes: Ireland and Australia are the most brazen examples here, offering generous tax subsidies for private insurance plans which are openly marketed as providing faster access to medically necessary care (Duckett and McDonald, 2016; Thomas, 2016). The logic of these foreign systems is echoed in the Cambie challenge, arguing that a parallel private tier will relieve pressure on the public system, and drive improvements in quality through competition. Of course, this argument for competition has superficial plausibility alone as there is no financial loss for public hospitals if wealthier patients drift to private institutions.

While there is much talk in Canadian debates of allowing 'choice' in health care financing (Flood and Haugan, 2010), little attention is paid to the myriad regulatory challenges that surface when a health system actively embraces - and comes to rely upon - a parallel private tier. Beyond tax subsidies [which evidence shows to be a regressive means by which to publicly subsidize privilege; see Stabile (2001) and Devlin et al. (2011)], both Ireland and Australia now impose penalties to compel individuals to enrol and/or maintain private coverage from an early age (Duckett and McDonald, 2016; Thomas, 2016). In Australia, this has led to a perverse situation where many have taken to purchasing low-cost, junk policies to avoid penalties. The Australian government is now looking at regulatory reform to make private policies more reliable and transparent (Davey, 2016). Experts are increasingly convinced that parallel private health insurance is of little or no benefit to Australians and they are growing more vocal as the studies mount demonstrating this point (McAuley, 2016).

\section{Financial disincentives on the supply side of the health care market}

As an alternative or complement to regulating private demand by patients for parallel privately financed health care, many countries take steps to regulate supply - eliminating or reducing providers' ability to profit in the private sector. Such restrictions can operate either within a public system, or across the public/ private divide. Within a public system, providers can be bound to a fixed fee schedule and prohibited from charging patients any additional amounts; the CHA penalties for extra-billing attempts to achieve this in Canada and accordingly all provinces have enacted laws outlawing extra-billing for medically necessary hospital and physician services. 
A similar approach is taken, for example, in Japan, where all providers are bound to a national fee schedule, negotiated bi-annually with the Ministry of Health, Labour and Welfare. While the Netherlands employs a 'market competition' model - wherein all residents are mandated to purchase coverage in a regulated market where private insurers in turn compete on quality and price - the Dutch Health Care Authority establishes maximum prices for each health care service. There have been isolated attempts to launch 'preferential treatment plans', where insurers contract with hospital to ensure their enrolees jump the queue. Such arrangements were deemed to violate the Dutch health law's (Wet marktordening gezondheidszorg) rule on maximum pricing (den Exter, 2016).

France partly embraces this approach as well, setting a national fee schedule and allowing only select 'sector 2' physicians to extra-bill patients above those rates. As of 2013, sector 2 physicians are subject to penalties for 'excessive' extra-billing, defined as more than $150 \%$ of the official tariffs (Chevreul et al., 2015). Even in the United States - a country known for its embrace of the free market - there are regulatory measures in place to discourage extra-billing within medicare (the public insurance scheme for those aged 65 and over). 'Participating providers' in US medicare receive a higher reimbursement rate, in exchange for relinquishing their right to extra-bill patients; it is possible to opt-out and retain the right to extra-bill medicare patients, but due to the financial disincentives, this accounts for only 5\% of providers (Mantel and Westergren, 2016).

These restrictions on extra-billing play an important role in preventing financial access barriers to publicly insured services. A separate question is whether providers are subject to price controls even when caring for patients outside the public system (i.e. those physicians who have opted-out of the public medicare system completely). In Canada, the provinces of Nova Scotia, Ontario and Manitoba currently limit private billing in this way (Flood and Archibald, 2001). From the OECD countries we have reviewed in our study, we have not yet found a similar attempt control the price of purely private care in this way. But this does not necessarily signal openness to private care: in many countries (e.g. Japan, the Netherlands) demand for care entirely outside of the universal scheme appears largely non-existent, such that legislating price controls would be a solution in search of a problem.

\section{Restrictions on private practice for particular categories of physician}

Above we described the restrictions on 'dual practice' that operate in some Canadian provinces, requiring physicians to opt-out entirely from medicare if they wish to bill patients privately for publicly insured physician services - a risky path, taken by only about $2 \%$ of physicians (Canadian Foundation for Health care Improvement, 2014). Other countries take an approach of limiting dual practice to particular categories of physicians. In the United Kingdom, for example, the training and certification process effectively requires junior physicians to work exclusively in the public sector (Botchway and Newdick, 2016). 
In our previous discussion of extra-billing, we mentioned France's 'sector 2' physicians, who are uniquely permitted to bill patients above the national tariffs. When first introduced in 1980, sector 2 status was offered as a quid pro quo for physicians willing to forgo sickness and pension benefits. At the time, French policymakers assumed that, given the ample supply of physicians, market competition would prevent excessive migration of physicians to sector 2 and discourage unreasonable extra-billing - a flawed assumption, as it turns out, which lawmakers are now addressing with penalties (Poullier and Sandier, 2000).

\section{Contractual measures to limit inequities from parallel private insurance}

To this point, we have been discussing statutory and regulatory measures that tamp down potential inequities from parallel private finance. Some countries largely forego these restrictions or they do not work given their particular context, but rein in providers contractually. England for example has little by way of traditional regulation of private care, but maintains a comparatively small private sector, comprising only $16 \%$ of total health care spending compared with an OECD average of $28 \%$ (OECD, 2014), with only $10.6 \%$ of the population holding parallel private coverage (LaingBuisson, 2017). ${ }^{4}$ While specialists working for the NHS are technically permitted to engage in dual practice, most are salaried and contractually bound to a full-time work schedule, limiting their ability to moonlight in the private sector (Flood et al., 2015). As one might imagine, this is a major bone of contention, with contract negotiations between the government and the British Medical Association routinely breaking down over the issue of public-private work hours (The Guardiant, 2004). Recently, NHS England (2017) issued revised conflict of interest guidelines, requiring that clinicians report the nature, location and time of their private sector activities. Similar contractual provisions operate in Norway and Sweden, where specialists are generally salaried by hospitals, where they are bound to a full-time work schedule and must report any outside activities that conflict with these obligations (Norheim and Søren, 2016a, 2016b, respectively). A contract binding specialists to a busy and diverse work schedule in the public system seems a less viable option in Canada, where physicians have grown accustomed over a halfcentury to a much higher level of independence - and have put their formidable lobbying power behind maintaining that independence (Hughes Tuohy, 1999).

Here again, Australia stands out as having followed an opposite path. The country's Medical Association, fearing that physicians would be forced to work for a salary in the public system, successfully lobbied to have a 'Civil conscription'

4 It is estimated that about $50 \%$ of NHS consultants engage in private practice. (http://www.bbc.com/ news/health-37415587). However, this statistic is likely to mislead readers, unless accompanied by data on how much time is spent moonlighting in private practice. That data is not available: NHS England pressed for transparency on this front in the fall of 2016, requiring that consultants declare income from private work. The requirement was soon abandoned in the face of pushback from physicians. See http://www. pharmaceutical-journal.com/news-and-analysis/news-in-brief/nhs-england-drops-requirement-for-cliniciansto-declare-earnings-from-private- 
provision added to the Australian Constitution in 1946 prohibiting the national government from 'conscripting' individuals into service for the country's health care system. The provision's interpretation has been debated in the courts, with the High Court most recently ruling, in General Practitioners Society $v$ Commonwealth (1980), that the test for civil conscription is whether government actions 'amount to a practical compulsion to perform a professional service'. In a particularly audacious challenge, which reached the High Court before being rejected, it was argued that the Civil conscription provision was violated by a requirement that physicians not overservice patients (Duckett and McDonald, 2016).

In other countries, contracting at the level of hospitals is used as a policy lever for equity and efficiency goals. In Japan for example, the Ministry of Health, Labour and Welfare is empowered by law to deny designation as a 'contracted medical facility' to private hospitals and clinics established in over-served areas - a de facto sanction that has a decisive dampening effect on the supply private hospitals, according to our experts (Kasagi and Kawaguchi, 2016). At the opposite end of the spectrum is Ireland, which has allowed privately insured patients to receive preferential treatment at public hospitals, billed at rates that do not cover the full economic cost (Thomas, 2016).

\section{Conclusion and future policy options: into the looking glass}

Charter challenges to laws inhibiting a larger tier of parallel private finance are winding their way through the courts. Whilst many health services researchers think the evidence supports one-tier medicine (Commission on the Future of Health Care in Canada, 2002), the court will not readily adopt this received wisdom because of the legal standard for adjudicating Charter rights. Having found that long wait times jeopardize a patient's security of the person under s. 7 of the Charter which protects rights to life and security of the person, both of which are arguably impacted by long wait times, the government will need to demonstrate that its existing restrictions on private finance are necessary to protecting the public system. The fact that other countries appear to achieve access and equity within their respective public health care systems and permit somewhat of a larger role for private financing serves to put Canadian governments on the back-foot from an evidentiary perspective.

The critical question - both to the disposition of the case, and for a provincial government if the court requires it to reform the legislation protecting the public health care system - is how to translate what we observe in other countries with respect to the regulation of public/private finance to a Canadian province. As part of the determination of whether existing laws restricting private finance are Charter compliant, the court will look at how countries approach regulating the public-private divide and consider if those means appear to achieve equity/access and (at least to some degree) permit individuals to avoid wait times by accessing a private tier. If a court finds that other countries achieve this balance through less 
intrusive means, then provincial laws are in serious jeopardy of being overturned. From that point it will be up to the government to reregulate to meet the court's concerns, but it still has policy options (Roach, 2008).

Canada is not (as frequently characterized by privatization proponents) in league only with North Korea and Cuba (Fund, 2005) in restricting room for a parallel private tier. Many other countries regulate to lessen the negative impacts of private finance - but which of these alternative approaches are a 'good fit' for Canada? Whilst it is undoubtedly clear that countries fall along a spectrum in their permissiveness of private finance for hospital and physician services, the real challenge is to translate another health care systems' approach to the particular Canadian context, given our own particular history (e.g. the allegiance to fee-forservice payment for and relative autonomy of physicians) and the other particular dynamics of the various provincial health care systems. Let us look at some of policy options that emerge in the particular Canadian context and translate that to the measures we see employed in other jurisdictions.

Provincial laws banning parallel private insurance are arguably at greatest risk in upcoming constitutional challenges, given the direct applicability of the Chaoulli precedent and because they are targeted directly at patients' themselves as opposed to the market incentives physicians face. In response to a judicial declaration that prohibitions on parallel private insurance are not constitutionally compliant, a provincial government has a variety of options at its disposal to tamp demand for a private tier. We outline them as follows, ranging from the most progressive through to the most regressive in terms of their respective impact on access:

i. Liberalize parallel private finance (i.e. remove the ban on buying parallel private insurance), but tamp demand for parallel private insurance by establishing waiting time guarantees. Although wait time guarantees are not without concerns, a recent systematic review deemed this 'the most common and effective policy tool to tackle long waiting times ...' (Siciliani et al., 2013). This would arguably be the most progressive response possible, in the sense of ensuring access according to medical need, and would constitute a genuine 'silver lining' for these Charter challenges to medicare. This is the approach taken by the Quebec government in the wake of the Chaoulli decision.

ii. Liberalize parallel private insurance but only for those services for which there are wait times and an assessment has been done showing a surplus of medical manpower such that permitting some drift to private-pay patients would not jeopardize supply in the public system. The concern in Canada is that many physicians want to live and work in downtown Vancouver and Toronto and whilst there may be 'surplus' physicians in these Centres, there are still shortages in many other parts of the country.

iii. Liberalize parallel private insurance, but mandate significant co-payments in the private sector to discourage patients from exploiting the safety valve offered by the private tier. Canadians have historically been resistant to co-payments fearing, correctly, that they post a threat to the CHA principle of accessibility. 
Mandatory co-payments for users of parallel private insurance would have the opposite effect, by erecting an access barrier to queue-jumping by comparatively affluent patients. Co-payments could be directly paid to the private service provider or collected by the government as a form of tax, as Saskatchewan has proposed with its private MRI tax.

iv. Lift or ease restrictions for private finance but only for those services for which there are wait times. One precondition for this strategy, which surely must be addressed regardless, is the current lack of systematic data collection on wait times in Canada. A deeper concern is that this response, pursued in isolation, may result in medical manpower being syphoned from the public to the private spheres, in precisely those areas where wait times are worst.

v. To permit substitutive private health insurance, along the lines of the German health care system, where those who opt to 'go private' are dis-enrolled entirely from medicare. This substitutive private stream would require heavy regulation, to ensure that patients have reliable, comprehensive coverage over a lifetime, such that they are not a liability for the public system in times of economic recession. However, the German system suggests that the number of individuals who would completely opt-out of the public system would be relatively small.

vi. The final and most regressive option in our view would be to normalize private insurance, as in Ireland and Australia, by encouraging the middle-class to purchase same through providing greater tax subsidies and/or requiring the purchase of private insurance by those in higher income brackets. There are - as Steven Duckett indicates when discussing the Australian context in this special volume - significant regressive effects that will flow from such an initiative but it may be appealing to provinces of more conservative ideology and/or those looking to garner political support by cross-subsidizing with public dollars consumption of health care by the middle-class and wealthy. In the Canadian context we have to recognize that we already have a very significant role for private health insurance in our system, as it is our primary means of finance for community-based pharmaceuticals and dental care. With approximately $66 \%$ of Canadians already holding private health insurance, we need to model the impact on employment rates of effectively increasing the cost of employment by loading in an expectation of expanding private health insurance to cover twotier private health care (Gruber, 1994).

As indicated, laws banning dual practice are also common in provinces across Canada and it is less certain that such laws will be found non-compliant with the Charter, given they are not directed at the individual seeking to avoid public sector queues but at physicians who wish to be paid by public medicare. However, given that most countries do allow some limited form of dual practice and there may be evidence that at least in some specialties (e.g. orthopaedic surgery) are not presently able to be fully employed in public medicare because of limited operating room time in public hospitals, then there is the prospect that a court may find a complete ban on dual practice not to be constitutionally compliant. A provincial government could, in response to a judicial declaration that such a law is not 
constitutionally compliant, explore alternative approaches to stanching the supply of medical human resources to a parallel private tier:

i. Permit dual practice without reservation. One concern is that this approach, particularly if combined with liberalization of private health insurance, will result in a significant migration of manpower from the public to the private spheres. This concern may manifest itself in a diverse ways, whether through physicians migrating to urban areas where there is stronger demand for privately financed care (leaving rural areas under-serviced), or by physicians staying in place but devoting a growing portion of their workday to private-pay patients.

ii. Permit dual practice but only for certain kinds of doctors. In some jurisdictions, only certain doctors are permitted to offer their services for unrestricted private payment and not others. This can be problematic if this privilege is only bestowed on more senior physicians, diluting their expertise from the public health care system. Provincial governments could perhaps respond by permitting certain numbers of doctors in sectors where there is an 'over-supply' in certain locales (where Canadian physicians cannot find jobs or are not fully employed in the public system) to provide care to both public-pay and private-pay patients. A possible concern here is that physicians would stream into these locales, seeking to profit from dual practice.

iii. Permit dual practice but ensure a healthy supply of medical manpower in the public system by requiring all physicians working in the public system to enter into contracts stipulating the length of time they will work in the public system and their duties and/or restricting the time spent working privately. This is the English model, which at first glance we may wish to emulate because of how well this system appears to outperform Canada in comparative evaluations of wait times (Schneider et al., 2017). But it is worth noting that England's success with wait times reduction is relatively recent (Siciliani et al., 2013) and seems to have little or nothing to do with the English approach to regulating the public/private divide and is much more clearly correlated with a commitment to a 18 weeks wait time guarantee and a system of 'targets and terror' throughout to achieve same. ${ }^{5}$ Moreover, even if Canada followed the English model, given the particular history of the relationships between Canadian governments and physician groups, one would have to place extremely long odds on successfully moving physicians from fee-for-service payment regimes to salaried contracts that regulate the amount of time they work in the public and private sectors.

iv. Permit dual practice but heavily regulate the price of care delivered in the private sphere (e.g. private care may only exceed public fee-for-service tariffs by $n \%$ ), thereby limiting the financial incentives for physicians to engage in private practice. Though an imperfect solution, this approach arguably has greater prospect of success in negotiations with physicians. The fact that many Western European countries regulate the price of physician services (e.g., France, the Netherlands) may mean that this approach is more resistant to constitutional challenge. Price regulations on the supply side might be complemented by disincentives on the demand side, such as our suggestion of mandating significant co-payments for parallel private insurance plans.

5 It appears the NHS may retreat now from this target (Campbell, 2017). We will need to follow what now happens to wait times and the drift from the public to private sectors. 
In sum there are complex considerations for provincial governments if they are forced by courts to reform their existing laws to protect public medicare. As they do so they will not be able to readily shop from other countries for an off-the-shelf remedy. Any reform will have to be adapted and filtered through Canada's own history and dynamics of its own particular health care system. As the time from a court judgment till the time point that a government must execute a new policy is relatively short (12 months is normal) Canadian governments need to prepare policy scenarios.

\section{Acknowledgments}

The authors would like to thank Richard Schuett for his excellent research assistance.

\section{References}

Botchway, S. and C. Newdick (2016), 'England country report'. Expert report prepared for CIHR project, A Comparative Evaluation of Two-Tier Care and the Relationship to Wait Times, http://ottawahealthlaw.ca/twotiercomparative [7 February 2018].

Cambie Surgeries et al. (2016), 'Opening Statement of the Plaintiffs', http://www.savemedicare. ca/court_documents [7 February 2018].

Campbell, D. (2017), 'NHS "waving white flag" as it axes 18-week waiting time operation target', The Guardian, 31 March, https:/www.theguardian.com/society/2017/mar/31/ nhs-surgery-target-operations-cancelled-simon-stevens [12 April 2017].

Canadian Foundation for Healthcare Improvement (2014), Healthcare Priorities in Canada: A backgrounder, Ottawa: CFHI.

Chevreul, K., K. Berg Brigham, I. Durand-Zaleski and C. Hernández-Quevedo (2015), 'France: health system review', Health Systems in Transition, 17(3): 1-218.

Commission on the Future of Health Care in Canada (Chair: Roy Romanow) (2002), Building on Values: The Future of Health Care in Canada. Commission on the Future of Health Care in Canada.

Davey, M. (2017), 'Experts agree private health insurance is broken. But how can it be fixed?', The Guardian, 17 November, https://www.theguardian.com/australia-news/2016/nov/18/ experts-agree-private-health-insurance-is-broken-but-how-can-it-be-fixed [10 April 2017].

Day, B. (2015), 'Rebuttal from Brian Day: my prescription for Canada's health care', National Observer, 18 June, http://www.nationalobserver.com/2015/06/18/opinion/rebuttalbrian-day-my-prescription-canadas-health-care [7 February 2018].

den Exter, A. (2016), 'Netherlands Country Report'. Expert report prepared for CIHR project, A Comparative Evaluation of Two-Tier Care and the Relationship to Wait Times, http:// ottawahealthlaw.ca/twotiercomparative [7 February 2018].

Devlin, R. A., S. Sarma and Q. Zhang (2011), 'The role of supplemental coverage in a universal health insurance system: some Canadian evidence', Health Policy, 100(1): 81-90.

Duckett, S. and F. McDonald (2016), 'Australia Country Report'. Expert report prepared for CIHR project, A Comparative Evaluation of Two-Tier Care and the Relationship to Wait Times, http://ottawahealthlaw.ca/twotiercomparative [7 February 2018].

Flood, C. M. (2008), 'Chaoulli: political undertows and judicial riptides', Health Law Journal, 17(Special Issue): 211-235. 
Flood, C. M. and T. Archibald (2001), 'The illegality of private health care in Canada', Journal of the Canadian Medical Association, 164(6): 825-830.

Flood, C. M. and L. Hardcastle (2007), 'Private sale of cancer drugs in Ontario's Public Hospitals: tough issues at the public/private interface in health care', McGill Health Law Journal, 1(1): 5-21.

Flood, C. M. and A. Haugan (2010), 'Is Canada odd? A comparison of European and Canadian approaches to choice and regulation of the public/private divide in health care', Health Economics, Policy and Law, 5(3): 319-341.

Flood, C. M., P. Allen, B. Thomas and K. Walker (2015), 'Restricting private-sector practice using contracts', Journal of the Canadian Medical Association, 187(8): 583-586.

Frisina, L. and A. Schmid (2016), 'Germany Country Report'. Expert report prepared for CIHR project, A Comparative Evaluation of Two-Tier Care and the Relationship to Wait Times, http://ottawahealthlaw.ca/twotiercomparative [7 February 2018].

Fund, J. H. (2005), 'Canada's "Free” health care has a high price tag', The Wall Street Journal, 12 August, https://www.wsj.com/articles/SB112381432071311723 [22 February 2018].

General Practitioners Society of Australia v Commonwealth and others (1980), 145 CLR 532, High Court of Australia.

Gruber, D. (1994), 'The incidence of mandated maternity benefits', The American Economic Review, 84(3): 622-641.

Hogg, P. W. and A. A. Bushell (1997), 'The Charter dialogue between courts and legislatures (or perhaps the Charter of rights isn't such a bad thing after all)', Osgoode Hall Law Journal, 35(1): 75-124.

Hughes Tuohy, C. (1999), Accidental Logics: The Dynamics of Change in the Health Care Arena in the United States, Britain, and Canada, New York: Oxford University Press.

Kasagi, E. and H. Kawaguchi (2016), 'Japan Country Report'. Expert report prepared for CIHR project, A Comparative Evaluation of Two-Tier Care and the Relationship to Wait Times, http://ottawahealthlaw.ca/twotiercomparative [7 February 2018].

LaingBuisson (2017), 'Demand for private medical cover increases as corporates extend schemes'. 16 January, https://www.laingbuisson.com/laingbuisson-release/demand-privatemedical-cover-increases-corporates-extend-schemes/ [7 February 2018].

Manfredi, C. P. (2005), 'Déja Vu All Over Again: Chaoulli and the Limits of Judicial Policymaking', in C. M. Flood, K. Roach and L. Sossin (eds), Access to Care, Access to Justice: The Legal Debate Over Private Health Insurance in Canada, Toronto, ON: University of Toronto Press, 139-160.

Mantel, J. and A. Westergren (2016), 'United States Country Report'. Expert report prepared for CIHR project, A Comparative Evaluation of Two-Tier Care and the Relationship to Wait Times, http://ottawahealthlaw.ca/twotiercomparative [7 February 2018].

Marchildon, G. P. (2014), 'The three dimensions of universal Medicare in Canada', Canadian Public Administration, 57(3): 362-382.

McAuley, I. (2016), 'Private health insurance and public policy', Paper presented at 2016 Health Insurance Summit, Sydney, 28 July, http://cpd.org.au/wp-content/uploads/2016/ 07/PHI-conference-July-2016.pdf [20 March 2017].

Mulgrew, I. (2017), 'Medicare constitutional challenge adjourns in muddle', Vancouver Sun, 10 April, http://vancouversun.com/news/local-news/ian-mulgrew-medicare-constitutionalchallenge-adjourns-in-muddle [20 April 2017].

Norheim, O. F. and P. Søren (2016a), 'Norway Country Report'. Expert report prepared for CIHR project, A Comparative Evaluation of Two-Tier Care and the Relationship to Wait Times, http://ottawahealthlaw.ca/twotiercomparative [7 February 2018]. 
Norheim, O. F. and P. Søren (2016b), ‘Sweden Country Report'. Expert report prepared for CIHR project, A Comparative Evaluation of Two-Tier Care and the Relationship to Wait Times, http://ottawahealthlaw.ca/twotiercomparative [7 February 2018].

NHS England (2017), 'Managing conflicts of interests in the NHS: guidance for staff and organisations', https://www.england.nhs.uk/wp-content/uploads/2017/02/guidance-managingconflicts-of-interest-nhs.pdf [20 August 2017].

Ontario Health Coalition (2017), 'Private clinics and the threat to public medicare in Canada: results of surveys with private clinics and patients', Ontario Health Coalition, Toronto, ON, www.ontariohealthcoalition.ca [20 August 2017].

Organisation for Economic Co-Operation and Development (OECD) (2014), 'How does the United Kingdom compare?', http://www.oecd.org/unitedkingdom/Briefing-NoteUNITED-KINGDOM-2014.pdf [7 February 2018].

Piotrowski, J. (2013), 'Health policy brief: excise tax on "Cadillac" plans', Health Affairs, 12 September, https://www.healthaffairs.org/do/10.1377/hpb20130912.565029/full/ [7 February 2018].

Poullier, J.-P. and S. Sandier (2000), 'France', Journal of Health Politics, Policy and Law, 25(5): 899-905.

Roach, K. (2005), 'The Courts and Medicare: Too Much or Too Little Judicial Activism', in C. M. Flood, K. Roach and L. Sossin (eds), Access to Care, Access to Justice: The Legal Debate over Private Health Insurance in Canada, Toronto, ON: University of Toronto Press, 184-206.

Roach, K. (2008), 'The Challenges of Crafting Remedies for Violations of Social, Economic and Cultural Rights', in M. Langford (ed.), Social Economic Rights Jurisprudence: Emerging Trends in International and Comparative Law, Cambridge: Cambridge University Press, 46-58.

Schneider, E. C., D. O. Sarnak, D. Squires, A. Shah and M. M. Doty (2017), 'Mirror, Mirror 2017: International Comparison Reflects Flaws and Opportunities for Better U.S. Health Care', The Commonwealth Fund, July.

Shingler, B. and J. Montpetit (2016), 'Ottawa threatens to cut Quebec's health payments over user fees', 19 September, http://www.cbc.ca/news/canada/montreal/quebec-gaetanbarrette-user-fees-philpott-1.3768799 [7 February 2018].

Siciliani, L., M. Borowitz and V. Moran (eds) (2013), Waiting Time Policies in the Health Sector: What Works?, Paris: OECD Publishing.

Stabile, M. (2001), 'Private insurance subsidies and public health care markets: evidence from Canada', Canadian Journal of Economics, 34: 921-942.

The Guardian (2004), 'Q\&A: the consultant contract', 4 January, https://www.theguardian. com/society/2004/jan/05/health.politics [7 February 2018].

Thomas, S. (2016), 'Ireland Country Report'. Expert report prepared for CIHR project, A Com parative Evaluation of Two-Tier Care and the Relationship to Wait Times, http://ottawa healthlaw.ca/twotiercomparative [7 February 2018].

Tuohy, C., C. M. Flood and M. Stabile (2004), 'How does private finance affect public health care systems? Marshaling the evidence from OECD nations', Journal of Health Politics, Policy and Law, 29: 359-396.

UK Department of Health (2004), 'A code of conduct for private practice', http://www.dh.gov. uk/prod_consum_dh/groups/dh_digitalassets/documents/digitalasset/dh_096576.pdf [7 February 2018].

UK Department of Health (2009), 'Guidance on NHS patients who wish to pay for additional care', http://www.dh.gov.uk/prod_consum_dh/groups/dh_digitalassets/documents/digitalasset/ dh_096576.pdf [12 April 2017]. 